\title{
Atypical Peritoneal Fluid
}

National Cancer Institute

\section{Source}

National Cancer Institute. Atypical Peritoneal Fluid. NCI Thesaurus. Code C160822.

A result that the peritoneal fluid is atypical. 